\title{
Perimenopause vasomotor symptoms, coronary atherosclerosis and risk of myocardial infarction during menopause: the cardiologist's perspective
}

\author{
Stefano Savonitto ${ }^{1}$, Luca A. Ferri' ${ }^{1}$, Delia Colombo ${ }^{2}$ \\ ${ }^{1}$ Division of Cardiology, Manzoni Hospital, Lecco, Italy \\ ${ }^{2}$ Clinical Pharmacology, Milan, Italy
}

\begin{abstract}
Myocardial infarction (MI) is rare in pre-menopausal women, and in most cases has a gender-specific pathogenesis. After menopause, MI incidence increases gradually to equalize men's rate in the eighth decade of age, with similar pathogenesis. This epidemiological observation has raised a number of hypotheses on the protective effect of estrogen against atherosclerosis and its related diseases. However, MI has a multifactorial pathogenesis with variable contributions of inflammation, eroded or ruptured atherosclerotic plaques, vasoconstriction and thrombosis. Whether perimenopausal vasomotor symptoms are associated with a better, worse or neutral effect on the risk of myocardial infarction has long been disputed. The recent finding of the LADIES ACS study that women reporting transitional vasomotor symptoms have earlier onset myocardial infarction, as compared to women without symptoms, despite similar risk factors and extent of coronary angiographic disease, supports the hypothesis that endothelial dysfunction, or other vasoconstrictive mechanisms, may play a key role in precipitating an acute coronary syndrome at an earlier age. These factors, rather than other atherosclerotic markers, should be specifically investigated in order to elucidate the so far elusive link between vasomotor symptoms and risk of MI.
\end{abstract}

Key words: myocardial infarction, cardiovascular disease, menopause, vasomotor symptoms.

\section{Introduction}

The risk of myocardial infarction (MI) increases with age, with women experiencing a 10-year advantage as compared to men, in terms of both incidence [1] and coronary atherosclerosis [2]. Whether this delay in atherosclerosis and $\mathrm{MI}$ risk is attributable to the protective effect of estrogen [3] or to a more favorable risk factor profile in women [4] has been a matter of long debate [5]. However, although the final mechanisms of MI (in most cases plaque rupture or erosion) are remarkably similar in both sexes, particularly in ST-elevation MI [6], other pathogenetic actors come into play [7], particularly in younger women. The multiplicity of these mechanisms, and their relation to the menopause transition time, are briefly discussed in the present review.

\section{Risk factors and the precipitating mechanisms of myocardial infarction in men and women}

There is no doubt that the most important study in cardiovascular medicine has been the Framingham Heart Study [8]. This study began in 1948, when 2336 men and 2873 women between the ages of 28 and 62 years were enrolled in a prospective investigation of determinants of cardiovascular disease, and identified those clinical conditions (hypertension, diabetes, high blood cholesterol, smoking, family history, low physical activity, among others) that were associated with the subsequent development of cardiovascular events, including MI. The importance of the study resides in the fact that almost all these risk factors are modifiable by either lifestyle of pharmacological interventions, with a remarkable impact on health policies and drug development which were the basis of the reduction in $\mathrm{MI}$, stroke and heart failure rates starting in the 1980s [9]. These risk factors have been confirmed in a number of subsequent longitudinal studies, but can also be easily recognized in everyday practice of cardiology, since MI patients do share those risk factors with higher frequency as compared to the general population. The final common pathway of these risk factors is vascular atherosclerosis, which tends to be more precocious in men, possibly because women are protected by estrogen during fertile life [3].

Most studies investigating the cardiovascular trajectories of post-menopausal women (including the 


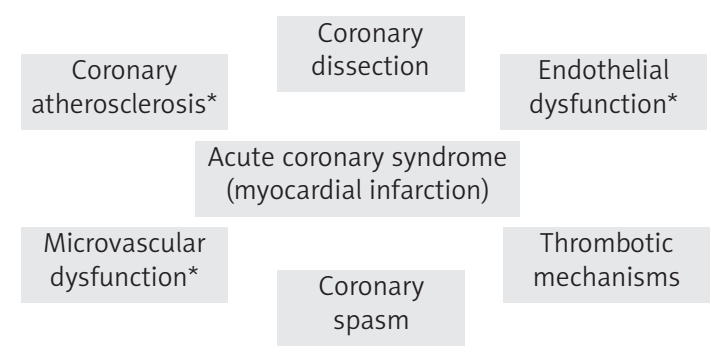

*Mechanisms most affected by the classical Framingham risk factors

Fig. 1. The multiplicity of pathogenetic mechanisms in Acute Coronary Syndromes and Myocardial Infarction (modified from [7])

cardiovascular effect of hormone therapy) have concentrated on direct or indirect imaging methods of vascular atherosclerosis, such as echo-Doppler intima-media thickness of the carotid arteries [10-14], angio CT and CT calcium score [14], coronary angiography $[2,15]$ and intravascular optical coherence tomography (OCT) [6].

However, besides (or in addition to) atherosclerosis, with its sequelae of coronary stenoses and plaque rupture, other mechanisms have been found to be involved in acute myocardial ischemia and infarction (Fig. 1). These include microvascular dysfunction and enhanced vasoconstriction of the epicardial vessels, which play a special role among women and require specific investigation $[16,19]$. These mechanisms, often viewed as early forms of atherosclerotic disease, should be considered in individual patients with acute coronary syndromes when no culprit artery can be identified at angiography. Occlusive coronary spasm can be found in patients with transient ST-segment elevation with or without angiographically visible stenosis, and is more typical of women. Coronary microvascular dysfunction is more commonly found in people, again more often women, with angina, signs of myocardial ischemia and no obstructed coronary arteries [20]. A rare $\mathrm{MI}$ cause, almost exclusive to young women, is coronary dissection, a nonatherosclerotic coronary disease often associated with fibromuscular dysplasia [21].

The therapeutic implications of discriminating the mechanisms at play in the individual patient are important, beyond the control of Framingham's risk factors which applies to all cases. When obstructive atherosclerosis is the dominant factor and severe occlusive stenoses are found, percutaneous or surgical revascularization is the indicated therapy. On the other hand, when microvascular dysfunction and vasoconstriction predominate, specific drug therapy is indicated. It is not uncommon that women with angina and no or nonobstructive coronary artery disease undergo repeated coronary angiographies each time they present with a non-ST-elevation type of acute coronary syndrome (ACS), and even in the case of stable angina [20].

The Women's Ischemia Syndrome Evaluation (WISE) group studies showed that, among women with sus- pected myocardial ischaemia and 'normal' coronary arteries, abnormal microvascular coronary function - defined as impaired coronary flow reserve (CFR) measured after intravenous or intracoronary adenosine administration - is associated with major adverse outcomes [18]. However, the total rate of death or MI events was less than $2 \%$ per year in this study.

\section{Perimenopause vasomotor sympłoms and vascular disease}

In the Ladies ACS study, vasomotor symptoms (VMS) during menopause transition were reported by $49 \%$ of post-menopausal women admitted with an acute MI. Despite the same menopausal age (mean 49.5 years, median 50 years) and fertility lifespan (mean 37, median 38 years), and the same coronary atherosclerotic burden, as measured angiographically using the Gensini score, women reporting VMS experienced their first MI four years earlier than women without VMS (Fig. 2) [22]. Probably because of VMS, symptomatic women had also used hormone replacement therapy more frequently than women without VMS (19\% vs. 9\%, $p=0.003$ ). Other signs of vascular disease (such as chronic kidney dysfunction and cerebrovascular disease) were significantly more frequent, perhaps due to older age, among women not reporting VMS. Overall cardiovascular events at 1 year did not differ between groups ( $19 \%$ vs. $22 \% ; p=0.5)$.

This is the first cross-sectional study correlating the presence of perimenopausal VMS with MI characteristics and outcome in post-menopausal women, since previous investigations on this issue had been longitudinal studies starting in midlife. These studies gave mixed results, since some of them found a higher risk of subsequent cardiovascular events among women with a history of VMS $[23,24]$, whereas others $[25,26]$ did not. The relation between timing of VMS and cardiovascular events in menopause has also been investigated, with mixed results: whereas the WISE study of women with stable coronary artery disease found elevated risk among women reporting VMS during early midlife (below the age of 42 years in that particular study) [27], an increased risk of clinical cardiovascular events and all-cause mortality was found in the Women's Health Initiative Observational Study (WHI-OS) among women reporting late-onset VMS (defined as VMS after menopause) [26].

The mechanisms behind the observed association of VMS with subsequent vascular disease and cardiovascular events have been investigated following two main streams: 1) VMS are associated with a higher risk-factor burden [28-30]; 2) VMS are associated with increased microvascular reactivity and impaired endothelial function $[18,25]$. The two potential mechanisms are not mutually exclusive, particularly with regard to endothelial 

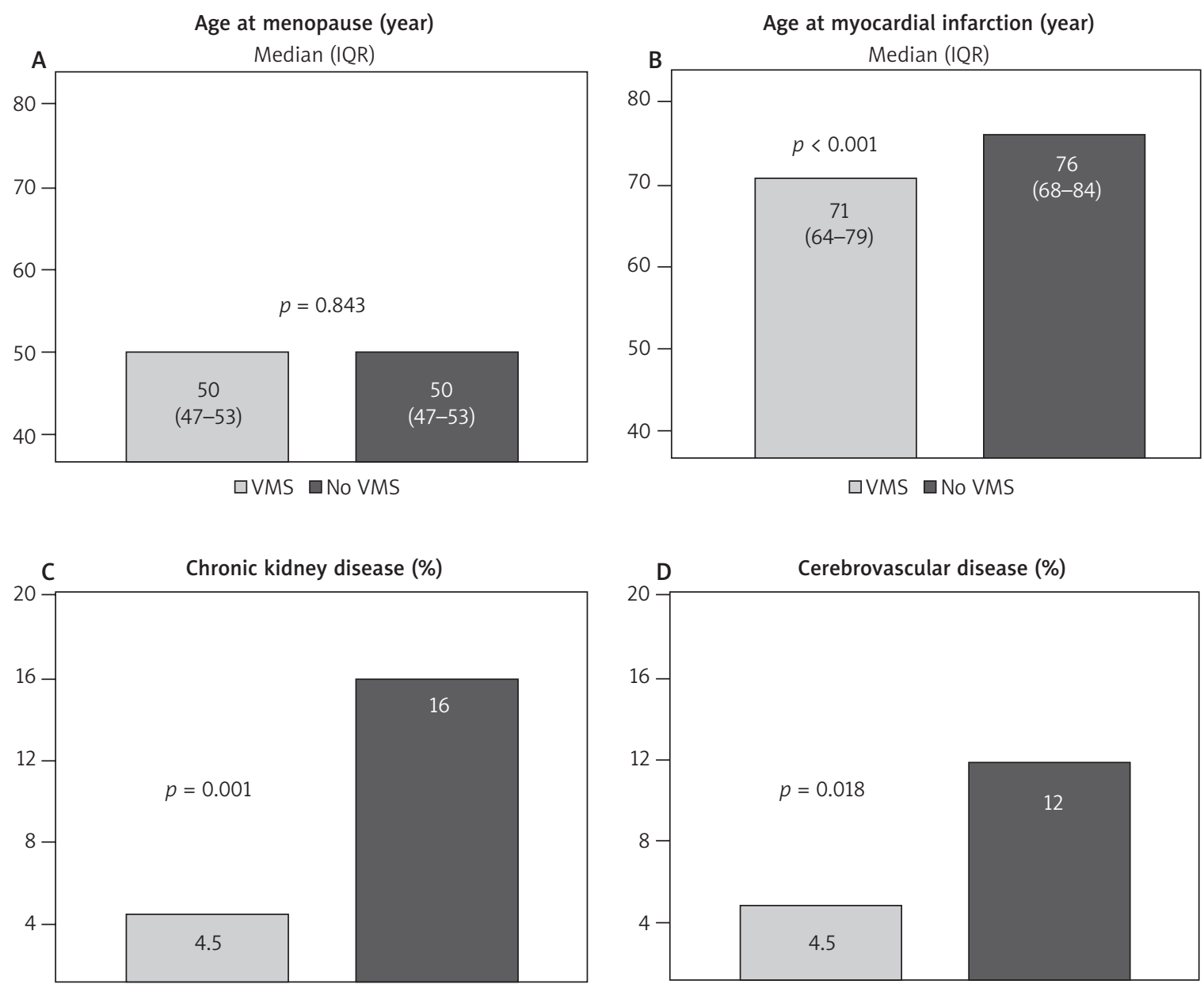

口VMS $\square$ No VMS

口VMS —No VMS

Fig. 2. Main findings of the Ladies ACS study as related to the presence (or lack of it) of vasomotor symptoms (VMS) (data from [22])

dysfunction, which may be considered an early stage of atherosclerosis. Endothelial dysfunction must be investigated using specific methods, such as brachial artery flow-mediated dilation (FMD) [27, 31, 32]. Coronary microvascular dysfunction, which should be considered as an etiology for ischemic heart disease with signs and symptoms of myocardial ischemia, but no obstructive coronary disease, should be either investigated using coronary vasoreactivity testing as the gold standard [16, $18,19]$, or taken for granted in the case of documented myocardial ischemia with no or nonocclusive coronary artery disease.

The most likely reason why the data on outcome have been so conflicting is the relatively low rate of death and $\mathrm{Ml}$ at follow-up among patients (mostly women) with angina and no obstructive coronary disease. The largest meta-analysis on this issue [20] identified 54 studies, reporting outcomes in a total of 35039 patients (mean age 56, male/female ratio 0.51 ) with angina and no obstructive CAD. After a median follow-up of 5 years, the pooled incidence of death and $\mathrm{MI}$ was $0.98 / 100$ person-years [95\% confidence interval $(\mathrm{Cl})$ 0.77-1.19\%], that is less than $1 \%$ per year. Factors associated with death and $\mathrm{MI}$ were dyslipidaemia $(p=0.016)$, diabetes $(p=0.035)$, and hypertension $(p=0.016)$. Studies enrolling patients with less-than-obstructive CAD showed a higher incidence of the primary outcome $(1.32 / 100$ person-years, $95 \% \mathrm{Cl}$ 1.02-1.62) compared with studies including only patients with 'entirely normal' coronary arteries (0.52/100 person-years, $95 \% \mathrm{Cl} 0.34-0.79$; $p<0.01$ ). Documented myocardial ischemia was not associated with worse outcome. However, these patients suffered from a high rate of recurrent hospitalizations.

\section{Conclusions}

Transitional VMS have been associated with adverse cardiovascular outcomes during menopause. However, their association with hard ischemic endpoints (such as death or $\mathrm{MI}$ ) is not proven, probably due to the low rate of these events in the studies. There is no evidence of more severe coronary atherosclerosis among post-menopausal women with a history of VMS, who, at least in the Ladies ACS study, may experience an MI earlier than women without such a history. The contribution of increased endothelial or microvascular dysfunction in 
cases with an $\mathrm{Ml}$ and nonobstructive coronary disease should be investigated with specific methods.

\section{Disclosure}

The authors report no conflict of interests.

\section{References}

1. Lerner DJ, Kannel WB. Patterns of coronary heart disease morbidity and mortality in the sexes: a 26-year follow-up of the Framingham population. Am Heart J 1986; 111: 383-390.

2. Savonitto S, Colombo D, Franco N, et al. Age at menopause and extent of coronary artery disease among post-menopausal women with acute coronary syndromes: a prospective age and sex-matched study. The LADIES ACS study. Am J Med 2016; 129: 1205-1212.

3. Mendelsohn ME, Karas RH. The protective effects of estrogen on the cardiovascular system. N Engl J Med 1999; 340: 1801-1811.

4. Koh HS, van Asselt KM, van der Schouw TY, et al. Heart disease risk determines menopausal age rather than the reverse. J Am Coll Cardiol 2006; 47: 1976-1983.

5. Mehta LS, Beckie TM, DeVon HA, et al.; on behalf of the American Heart Association Cardiovascular Disease in Women and Special Populations Committee of the Council on Clinical Cardiology, Council on Epidemiology and Prevention, Council on Cardiovascular and Stroke Nursing, and Council on Quality of Care and Outcomes Research. Acute myocardial infarction in women: a scientific statement from the American Heart Association. Circulation 2016; 133: 916-947.

6. Guagliumi G, Capodanno D, Saia F, et al.; OCTAVIA Trial Investigators. Mechanisms of atherothrombosis and vascular response to primary percutaneous coronary intervention in women versus men with acute myocardial infarction: results of the OCTAVIA study. JACC CardiovasC Interv 2014; 7: 958-968.

7. Marzilli M, Merz CN, Boden WE, et al. Obstructive coronary atherosclerosis and ischemic heart disease: an elusive link! J Am Coll Cardiol 2012; 60: 951-956

8. Dawber TR, Meadors GF, Moore FE. Epidemiologic approaches to heart disease: the Framingham Study. Am J Public Health 1951; 41: 279-286.

9. Nabel EG, Braunwald E. A tale of coronary artery disease and myocardial infarction. N Engl J Med 2012; 366: 54-63.

10. Hodis HN, Mack WJ, Lobo RA, et al. Estrogen in the prevention of atherosclerosis: a randomized, double-blind, placebo controlled trial. Ann Intern Med 2001; 135: 939-953.

11. Hodis HN, Mack WJ, Azen SP, et al. Hormone therapy and the progression of coronary-artery atherosclerosis in postmenopausal women. $\mathrm{N}$ Engl J Med 2003; 349: 535-545.

12. Herrington DM, Reboussin DM, Brosnihan KB, et al. Effects of estrogen replacement on the progression of coronary artery atherosclerosis. N Engl J Med 2000; 343: 522-529.

13. Waters DD, Alderman EL, Hsia J, et al. Effects of hormone replacement therapy and antioxidant vitamin supplements on coronary atherosclerosis in postmenopausal women: a randomized controlled trial. JAMA 2002; 288: 2432-2440.

14. Hodis HN, Mack WJ, Henderson VH, et al., for the ELITE Research Group. Vascular Effects of Early versus Late Postmenopausal Treatment with Estradiol. N Engl J Med 2016; 374: 1221-1231.

15. Lansky AJ, Ng VG, Maehara A, et al. Gender and the extent of coronary atherosclerosis, plaque composition, and clinical outcomes in acute coronary syndromes. JACC Cardiovasc Imaging 2012; 5: S62-72.

16. Dean J, Dela Cruz S, Mehta PK, Bairey Merz CN. Coronary microvascular dysfunction: sex-specific risk, diagnosis, and therapy. Nat Rev Cardiol 2015; 12: 406-414.

17. Aziz A, Hansen HS, Sechtem U, et al. Sex-Related Differences in Vasomotor Function in Patients With Angina and Unobstructed Coronary Arteries. J Am Coll Cardiol 2017; 70: 2349-2358.

18. Pepine CJ, Anderson RD, Sharaf BL, et al. Coronary microvascular reactivity to adenosine predicts adverse outcome in women evaluated for suspected ischemia results from the National Heart, Lung and Blood
Institute WISE (Women's Ischemia Syndrome Evaluation) study. J Am Coll Cardiol 2010; 55: 2825-2832.

19. Camici PG, Crea F. Coronary microvascular dysfunction. N Engl J Med 2007; 356: 830-840.

20. Radico F, Zimarino M, Fulgenzi F, et al. Determinants of long-term clinical outcomes in patients with angina but without obstructive coronary artery disease: a systematic review and meta-analysis. Eur Heart J 2018; 39: 2135-2146.

21. Saw J, Ricci D, Starovoytov A, et al. Spontaneous Coronary Artery Dissection. Prevalence of Predisposing Conditions Including Fibromuscular Dysplasia in a Tertiary Center Cohort. J Am Coll Cardiol Intv 2013; 6 : 44-52.

22. Ferri LA, Morici N, Franco N, et al.; Ladies ACS Investigators. History of vasomotor symptoms, extent of coronary artery disease and clinical outcomes after acute coronary syndromes in postmenopausal women. Menopause 2018; 25: 635-640.

23. Herber-Gast GCM, Brown WJ, Mishra GD. Hot flushes and night sweats are associated with coronary heart disease risk in midlife: a longitudinal study. BJOG 2015; 122: 1560-1567.

24. Gast GC, Pop VJ, Samsio GN, et al. Vasomotor menopausal symptoms are associated with increased risk of coronary heart disease. Menopause 2011; 18: 146-151.

25. Svartberg J, von Muhlen D, Kritz-Silverstein D, Barrett-Connor E. Vasomotor symptoms and mortality: the Rancho Bernardo Study. Menopause 2009; 16: 888-891.

26. Szmuilowicz ED, Manson JE, Rossouw JE, et al. Vasomotor symptoms and cardiovascular events in postmenopausal women. Menopause 2011; 18: 603-610

27. Thurston RC, Johnson BD, Shufelt CL, et al. Menopause symptoms and cardiovascular disease mortality in the Women's Ischemia Syndrome Evaluation (WISE). Menopause 2017; 24: 126-132.

28. Gast GC, Grobbee DE, Pop VJ, et al. Menopausal complaints are associated with cardiovascular risk factors. Hypertension 2008; 51: 1492-1498.

29. Cagnacci A, Cannoletta M, Palma F, et al. Menopausal symptoms and risk factors for cardiovascular disease in postmenopause. Climacteric 2012; 15: 157-162.

30. Franco OH, Muka T, Colpani V, et al. Vasomotor symptoms in women and cardiovascular risk markers: systematic review and meta-analysis. Maturitas 2015; 81: 353-361.

31. Thurston RC, Sutton-Tyrrell K, Everson-Rose SA, et al. Hot flashes and subclinical cardiovascular disease: Findings from the Study of Women's Health Across the Nation heart study. Circulation 2008; 118: 1234-1240.

32. Bechlioulis A, Kalantaridou SN, Naka KK, et al. Endothelial function, but not carotid intima-media thickness, is affected early in menopause and is associated with severity of hot flushes. J Clin Endocrinol Metab 2010; 95: 1199-1206. 